\title{
Lean mass plays a gender-specific role in familial resemblance for femoral neck bone mineral density in adult subjects
}

\author{
H. Blain • A. Vuillemin • C. Jeandel • P. Jouanny • \\ F. Guillemin • E. Le Bihan
}

Published online: 4 July 2006

(C) International Osteoporosis Foundation and National Osteoporosis Foundation 2006

The online version of the original article can be found at: http://dx.doi. org/10.1007/s00198-005-0062-1

H. Blain $(\varangle) \cdot$ C. Jeandel

Service de Medécine Interne-Gériatric, Centre de Prévention et de traitement des maladies du Vieillissement,

39, avenue Charles Flahault,

34295 Montpellier, Cedex 5, France

e-mail: h-blain@chu-montpellier.fr

\author{
A. Vuillemin · F. Guillemin \\ EA3444 "Epidémiologie clinique, Prévention, \\ Qualité de vie", Ecole de Santé Publique, \\ Faculté de Médecine, Université Henri Poincaré, \\ Nancy, France \\ P. Jouanny \\ Service de Gériatrie, CHU, \\ Rennes, France \\ E. Le Bihan \\ Faculty of Language and Literature, \\ Humanities, Arts and Education, University of Luxembourg, \\ Luxembourg, Luxembourg
}

This article was published with the authors in the wrong order. The correct order is as shown here.

In addition, the online HTML version of the article rendered the last author's name incorrectly. The correct name is that given here. 